\title{
Job Satisfaction and Intention to Leave According to the Size of the Organization
}

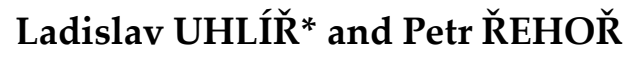 \\ 1 University of South Bohemia, České Budějovice, Czech Republic; uhlirl03@ef.jcu.cz; rehor@ef.jcu.cz \\ * Corresponding author: uhlirl03@ef.jcu.cz
}

\begin{abstract}
The issue of job satisfaction has been discussed by the researchers and managers of organizations for several decades. There are many different approaches to the issue. Currently, it is possible to find the research dealing with psychological aspects determining the level of job satisfaction, the research analyzing the role of satisfaction and work motivation and the research focused on the consequences of job satisfaction and dissatisfaction. This paper describes the differences in general job satisfaction depending on the size of the organization and the relationship between job satisfaction and the intention to leave current job. It was found that job satisfaction is significantly higher for employees of small organizations. The correlation between job satisfaction and the intention to leave was confirmed. Finally, it was found that in small organizations there is a significantly higher correlation between job satisfaction and the intention to leave than in large organizations. The data for the research are based on a questionnaire survey, attended by 4,728 respondents from the Czech Republic working in various industries and in the enterprises of various sizes.
\end{abstract}

Keywords: job satisfaction; intention to leave; size of the organization; employees

JEL Classification: J28; J63

\section{Introduction}

The issue of job satisfaction has been discussed by the researchers and managers of organizations for several decades. There are many different approaches to the issue. In relation to job satisfaction, the areas such as employee motivation, turnover, personal characteristics of employees, identification of the most important factors influencing job satisfaction, etc. are analyzed. It is also important to define the term correctly. Locke (1976) found a generally accepted definition, describing job satisfaction as a pleasant and positive emotional state of a person resulting from the evaluation of work and working experience.

At first glance, however, interchangeable terms may in fact describe different phenomena. As an example, Kollárik (1986) distinguishes the terms "job satisfaction" and "satisfaction with a job". The satisfaction with a job is related to specific work activities performed, its requirements and requirements for the employee; on the other hand the job satisfaction is satisfaction in a broader sense and it includes the factors such as the work environment and personality characteristics of the employee.

Nakonečný (2005) distinguishes the concepts of job satisfaction and satisfaction at work. The job satisfaction indicates satisfaction with work activities and performance, the 
satisfaction at work does not require any performance, as even person who has done nothing can be satisfied at work.

Satisfaction at the workplace can be also defined as the overall response of the employee to the organization and company, in terms of the individual's emotional status and behavior. Job satisfaction also measures to which extent there is a good individual-organization fit (Chou et al., 2019).

The issue of job satisfaction in relation to the formation of employee motivation is included in classical motivational theories. As an example, Maslow (1943) describes a person's motivation to act as an unsatisfied need, the needs being different and their type arrangement representing a well-known hierarchy of needs. If the needs of a person are not met at aiven level, dissatisfaction occurs. Herzberg (1959) then identified two types of factors - hygienic factors and motivators. If the hygienic factors are not sufficiently fulfilled, the employee is dissatisfied. On the contrary, the presence of the second group of factors, the known as the motivators, leads to employee satisfaction with a positive effect on motivation.

Possible consequences of job dissatisfaction are summarized by Clegg and Bailey (2008) in such a way that the dissatisfied employees are more prone to absences, turnover, late arrivals, long breaks, theft, aggression, using work for their personal use, intent to look for new jobs and drug use at the workplace. An unsatisfied employee has the tendency to evaluate the cost of quitting and searching for alternative jobs and it increases turnover intention (Mobley, 1982).

Turnover intention is defined as the subjective probability that an individual will change his or her job within a certain period of time (Henneberger \& Souza-Poza, 2004). Intention to leave current job has been studied by researches because of its important effect on productivity. Over the years, many studies have been done to identify significant predictors of turnover intention, such as job satisfaction, organizational commitment, administrative leadership or co-workers' job embedding (Park \& Johnson, 2019; Robson \& Robson, 2016). There is evidence from many countries and professions that overall job satisfaction has a significant negative association with turnover intention. For example teachers in USA (Ingersoll, 2001), teachers in Norway (Skaalvik \& Skaalvik, 2011), CTE health science teachers in USA (Park \& Johnson, 2019), nurses in USA (Derby-Davis, 2014),(Applebaum et al., 2010), social workers in England (Hussein et al., 2014), lecturers in Pakistan (Ali, 2007), prison staff in Turkey (Güres \& Sökmen, 2015), manufacturing workers in Malaysia (Tnay, Othman, Siong \& Lim, 2013), midwives in Jordan (Alnuaimi, Ali, \& Al-Younis, 2020) or workers of shipping industry in China (Yao \& Huang, 2018).

There are external and internal factors influencing job satisfaction. The external factors are independent of the individual, connected with the overall work environment. These include, for example, salary, working conditions, co-workers. The internal factors are linked to the personality of the employee and their relationship to the work activity itself (Štikar et al., 2003). Sokolová, Mohelská and Zubr (2016) describe significant differences in job satisfaction based on determinants such as gender, age, years of experience or size of the organization.

Research focused on the relationship between the organization size and job satisfaction suggest that employees of small businesses are the most satisfied and that job satisfaction 
decreases as the number of employees increases. With these results came for example Lang and Johnson (1994), Clark (1996), Tansel and Gazioglu (2013), or Sokolová, Mohelská, and Zubr (2016). Higher rate of job satisfaction in smaller organizations reports also Artz (2008), who examined the effect of performance rewards in organizations of various sizes.

Job satisfaction was also analyzed in the Czech Republic in the past, but there are only a few studies focused on this topic. The first empirical data on job satisfaction in the Czech Republic are available, since 1997 from the International Social Survey Programme (Franěk et al., 2014). Franěk and Večeřa (2008) or Sokolová, Mohelská, and Zubr (2016) focused their research on description of differences in job satisfaction between different group of employees, determined by gender, education level or age. In terms of international comparison, mention may be made, for example, of the research by Eskildsen, Kristensen, and Antvor (2010). The study compared data on job satisfaction from 22 European countries, with job satisfaction in the Czech Republic being the second lowest. The conclusions of this research thus confirmed the traditionally low value of job satisfaction in the Czech Republic, which results from previous research. E.g. Medgyesi and Róbert (2003) concluded that the Czech Republic belongs to the group of eight countries with the lowest level of job satisfaction in Europe. Similar results are reported by Večerník (2003). Borooah (2009) also recorded significantly lower job satisfaction in the countries of Central and Eastern Europe. These results are consistent with one of the latest research made by Sokolová and Mohelská (2019) who concluded, that overall job satisfaction in Czech Republic is relatively low.

\section{Methodology}

The data were obtained by a questionnaire survey, carried out in the first half of 2019. The questionnaire was created in the Google Forms interface and respondents were addressed through geographically local groups on social networks. These local groups are usually made up of people who live, work or study in the place. The groups for inserting the questionnaire were selected so that each district of the Czech Republic was represented. In total, up to 500,000 potential respondents in 120 groups were addressed; 4,728 questionnaires were completely completed, so the return rate is approximately $1 \%$.

There are a total of 48 questions in the questionnaire, of which 31 questions are focused on the issue of job satisfaction. These are the closed questions; with the respondents assessing their satisfaction with selected aspects of their working lives on a scale from 0 to 10, where 0 means absolute dissatisfaction and 10 means absolute satisfaction with the factor. The remaining 17 questions are of an identifying nature and made it possible to create several segments of the respondents, such as the income, branch and size of the enterprise, size of municipality, marital status, etc. For the purposes of the paper, three questions of the questionnaire are used - assessing general job satisfaction, assessing intention to leave current employment and size of the organization where respondents work.

The data are analyzed in two ways. The contingency tables in MS Excel are used to describe the sample, and determine the absolute and relative frequencies of the answers. Statistical testing of hypotheses is performed in the software of $\mathrm{R}$ and software 
STATISTICA 13. The characteristics of the sample in terms of classification into the monitored groups of the respondents for the purposes of the paper are reported in Table 1.

Table 1. The sample.

\begin{tabular}{|c|c|c|c|}
\hline \multicolumn{2}{|r|}{ Category } & \multirow{2}{*}{$\begin{array}{c}\text { Frequency in the sample } \\
\qquad 1,221\end{array}$} & \multirow{2}{*}{$\begin{array}{c}\text { Percentage } \\
26 \%\end{array}$} \\
\hline Gender & Male & & \\
\hline Genaer & Female & 3,507 & $74 \%$ \\
\hline \multirow{4}{*}{ Age } & Under 30 years & 1,514 & $32 \%$ \\
\hline & $30-44$ years & 2,190 & $46 \%$ \\
\hline & $45-59$ years & 938 & $20 \%$ \\
\hline & 60 years and older & 86 & $2 \%$ \\
\hline \multirow{7}{*}{ Education } & Primary & 115 & $2 \%$ \\
\hline & Secondary technical school & 772 & $16 \%$ \\
\hline & Secondary with a leaving examination & 2,008 & $42 \%$ \\
\hline & Higher professional school & 317 & $7 \%$ \\
\hline & Bachelor & 511 & $11 \%$ \\
\hline & Master & 930 & $20 \%$ \\
\hline & PhD. & 75 & $2 \%$ \\
\hline \multirow{4}{*}{$\begin{array}{l}\text { Employer size } \\
\text { (number of } \\
\text { employees) }\end{array}$} & Under 10 & 742 & $16 \%$ \\
\hline & $10-49$ & 1,148 & $24 \%$ \\
\hline & $50-249$ & 1,186 & $25 \%$ \\
\hline & 250 and more & 1,652 & $35 \%$ \\
\hline \multirow{5}{*}{ Marital status } & No partnership and dependent child & 792 & $17 \%$ \\
\hline & No partnership with a dependent child & 245 & $5 \%$ \\
\hline & In a partnership without a dependent child & 1,776 & $38 \%$ \\
\hline & In a partnership with a dependent child & 1,870 & $40 \%$ \\
\hline & Marital status not determined & 45 & $1 \%$ \\
\hline
\end{tabular}

Based on literature review, the following three hypotheses have been chosen to test in this study:

H1: Employees of organizations with up to 49 employees rate their level of job satisfaction better, than employees of organizations with 50 employees and more.

H2: Employees of organizations with up to 49 employees have a lower level of intent to leave their current job, than employees of organizations with 50 employees and more.

H3: In organizations with up to 49 employees is the relationship between job satisfaction and intent to leave more significant, than in organizations with 50 employees and more.

The hypotheses $\mathrm{H} 1$ and $\mathrm{H} 2$ were tested using the Welch's T-test of the agreement of the means for unequal variances. This method of hypothesis testing is a modification of the Student's t-test, which is suitable for use in comparing two sets of different sizes with unequal variances. The value of the test criterion is based on the following formula (Welch, 1947):

$$
t=\frac{\mu 1-\mu 2}{\sqrt{\frac{s_{1}^{2}}{N_{1}}+\frac{s_{1}^{2}}{N_{2}}}}
$$


For determining the existence of dependency between job satisfaction and intention to leave current job we used Pearson's Correlation Coefficient:

$$
r=\frac{\sum(x-\bar{x})(y-\bar{y})}{\sqrt{\sum(x-\bar{x})^{2} \sum(y-\bar{y})^{2}}}
$$

\section{Results}

\subsection{Hypothesis 1}

The first hypothesis assumes that employees of smaller organizations (fewer than 50 employees) rate their job satisfaction better, than employees of bigger organizations. In the questionnaire, respondents selected the size of their employer from four options according to the number of employees in accordance with the definition of SMEs. These options were: 1. Fewer than 10 employees, 2. 10-49 employees, 3. 50-249 employees, 4 . 250 employees and more. The results of job satisfaction for each category are shown in Table 2.

Table 2. Job satisfaction according to the size of the organization.

\begin{tabular}{|l|l|c|c|}
\hline \multicolumn{1}{|c|}{ Employees } & Mean & Standard deviation & $\mathbf{N}$ \\
\hline Fewer than $\mathbf{1 0}$ & 7.2075 & 2.6769 & 742 \\
\hline $\mathbf{1 0 - 4 9}$ & 6.9138 & 2.5153 & 1,148 \\
\hline $\mathbf{5 0 - 2 4 9}$ & 6.6020 & 2.4929 & 1,186 \\
\hline $\mathbf{2 5 0}$ and more & 6.5992 & 2.5606 & 1,652 \\
\hline
\end{tabular}

A look at Table 2 indicates that there might be a negative correlation between average level of job satisfaction and the size of the organization. The highest average satisfaction is shown by employees in the smallest companies. On the contrary, we recorded the lowest level of job satisfaction among employees of the largest organizations.

To test hypothesis H1, two groups of respondents were created from the data. Group A contains all the respondents who selected first two options for the size of organization they are working at (Fewer than 10 employees and between 10 and 49 employees). The respondents who selected remaining 2 options are included in group B. There are 1,890 respondents in group $\mathrm{A}$ and 2,838 in group $\mathrm{B}$.

In accordance with the above H1, the following null and alternative hypotheses are formulated:

$\mathrm{H} 0: \mu \mathrm{A}=\mu \mathrm{B}$

$\mathrm{HA}: \mu \mathrm{A}>\mu \mathrm{B}$

Table 3. H1 testing.

\begin{tabular}{|c|c|c|c|}
\hline Mean A & Mean B & $\mathbf{t}$ & p-value \\
\hline 7.0291 & 6.6004 & 5.6338 & $9.424 \mathrm{e}^{-9}$ \\
\hline
\end{tabular}

Conclusion: Based on the data as reported by Table 3, at the level of significance of $\alpha=0.05$, the null hypothesis is rejected in favor of the alternative hypothesis. The data of the 
research group show that employees of smaller organizations rate their job satisfaction significantly better than employees of bigger organizations.

\subsection{Hypothesis 2}

The second hypothesis assumes that employees of bigger organizations (with 50 and more employees) generally plan to change their current job more than employees of smaller organizations. The results of the question related to the intention to leave the current job are summarized in Table 4.

Table 4. Intention to leave the current job according to the size of the organization.

\begin{tabular}{|l|c|c|c|}
\hline \multicolumn{1}{|c|}{ Employees } & Mean & Standard deviation & $\mathbf{N}$ \\
\hline Fewer than $\mathbf{1 0}$ & 3.8059 & 3.7319 & 742 \\
\hline $\mathbf{1 0}-\mathbf{4 9}$ & 4.2134 & 3.6038 & 1,148 \\
\hline $\mathbf{5 0}-\mathbf{2 4 9}$ & 4.3642 & 3.5900 & 1,186 \\
\hline $\mathbf{2 5 0}$ and more & 4.2772 & 3.5970 & 1,652 \\
\hline
\end{tabular}

Looking at the Table 4 above, it is clear that employees in the smallest organizations have the lowest intention to leave their current job. The mean value of this intention is approximately 3.8 on a scale from 0 to 10 , where 0 means no intention to leave current job and 10 means maximum intention. Mean values of this intention in organizations with 10 and more employees are above 4.2. On the other hand, we can see the biggest value of standard deviation by the smallest organization. It indicates that in these organizations the intention to leave varies the most among their employees.

To test the hypothesis $\mathrm{H} 2$, we again use groups of respondents $\mathrm{A}$ and $\mathrm{B}$, as in testing hypothesis $\mathrm{H} 1$ earlier (fewer than 50 employees = group A; 50 employees and more = group B).

In accordance with the above $\mathrm{H} 2$, the following null and alternative hypotheses are formulated:

$\mathrm{H} 0: \mu \mathrm{A}=\mu \mathrm{B}$

HA: $\mu \mathrm{A}<\mu \mathrm{B}$

Table 5. H2 testing.

\begin{tabular}{|c|c|c|c|}
\hline Mean A & Mean B & $\mathbf{t}$ & p-value \\
\hline 4.0534 & 4.3136 & 2.4119 & 0.007956 \\
\hline
\end{tabular}

Conclusion: Based on the data as reported by Table 5, at the level of significance of $\alpha=0.05$, the null hypothesis is rejected in favor of the alternative hypothesis. The data of the research group show that employees of smaller organizations have lower level of intention to leave their job than employees of bigger organizations.

\subsection{Hypothesis 3}

Results of first two hypotheses, as well as the researches presented in the literature review indicate that there is a correlation between the level of job satisfaction and the intention to leave the organization. In this section, we would like to answer the question of 
whether there is a significant difference in the correlations of satisfaction and the intention to leave the current job between organizations of different sizes.

Pearson's correlation coefficient was used to verify the relation between job satisfaction and the intention to change current job. We confirmed a negative correlation between these two variables for organizations of all sizes. An overview of the coefficients thus obtained is in Table 6.

Table 6. Correlation between job satisfaction and intention to leave.

\begin{tabular}{|l|c|c|}
\hline \multicolumn{1}{|c|}{ Employees } & $\mathbf{r}$ & $\mathbf{N}$ \\
\hline Fewer than $\mathbf{1 0}$ & -0.7153 & 742 \\
\hline $\mathbf{1 0} \mathbf{4 9}$ & -0.6877 & 1,148 \\
\hline $\mathbf{5 0} \mathbf{2 4 9}$ & -0.6932 & 1,186 \\
\hline $\mathbf{2 5 0}$ and more & -0.6282 & 1,652 \\
\hline
\end{tabular}

Looking at the Table 6 we can see that the strongest correlation between job satisfaction and the intention to leave employment was found in companies with less than 10 employees. In small (10-49 employees) and middle organizations (50-249 employees) is the correlation coefficient approximately -0.69 . The smallest correlation was found for the largest organizations with 250 employees and more. But with value -0.6282 it is still medium strength correlation.

To test the hypothesis $\mathrm{H} 3$, we again use groups of respondents $\mathrm{A}$ and $\mathrm{B}$, as in testing previous hypotheses $\mathrm{H} 1$ and $\mathrm{H} 2$ (fewer than 50 employees = group A; 50 employees and more $=$ group $\mathrm{B})$.

In accordance with the above $\mathrm{H} 3$, the following null and alternative hypotheses are formulated:

H0: $r A=r B$

HA: $r A>r B$

Table 7. H3 testing.

\begin{tabular}{|c|c|c|}
\hline Pearson $\mathbf{r}-\mathbf{A}$ & Pearson $\mathbf{r}$ - B & p-value \\
\hline-0.7016 & -0.6543 & 0.0016 \\
\hline
\end{tabular}

Conclusion: Based on the data as reported by Table 7, at the level of significance of $\alpha=0.05$, the null hypothesis is rejected in favor of the alternative hypothesis. It means, that generally in organizations with up to 49 employees is a stronger correlation between job satisfaction and intention to leave than in enterprises with 50 employees and more.

However, this conclusion is the result of a statistical operation rather than a reflection of reality. If we look back at Table 6, we find that the difference in correlations between small (10-49 employees) and medium-sized organizations (50-249 employees) is very small and even slightly larger in medium-sized enterprises. The difference in correlation coefficients between group A and B is therefore caused only by a significantly lower value of correlation in the largest organizations. 


\section{Discussion and Conclusions}

In this paper, we tried find out whether there are differences in employee job satisfaction and the intention to leave the current job depending on the size of the organization in the Czech Republic. Based on the results of our questionnaire survey, we can state that significant differences were found in this area.

First of all, we found that people rate their job satisfaction best when they work in micro-enterprises that employ a maximum of 9 employees. With the growing number of employees, the average reported job satisfaction decreases. Based on data from our research group, we have shown that in organizations with up to 49 employees, employees have significantly higher job satisfaction than in organizations with 50 on more employees. This result is consistent with research by Sokolová, Mohelská and Zubr (2016). Their research carried out in 2013 and repeated in 2015 shows that the most satisfied are employees of companies with a maximum of 50 employees.

The second finding is that the intention to leave the current job is significantly higher for employees working in organizations with 50 and more employees. In connection with the first finding, we thus obtain the assumption of negative correlation between job satisfaction and the intention to leave employment.

This assumption was also confirmed. The average correlation regardless of the size of the organization has a value of -0.674 that is a relatively strong dependence. A closer look at the correlations in organizations of different sizes revealed significant differences. The correlation between job satisfaction and the intention to leave the organization is highest in micro, small and medium-sized enterprises with maximum of 249 employees. In contrast, for companies with more than 250 employees, the correlation is significantly lower. This means that employees in large organization do not reflect their level of job satisfaction in their plans to stay in the company or leave it as elastically as employees in smaller organizations.

These results can be practically beneficial for small and medium-sized enterprises and their management. If they want to keep existing employees, it is relatively more important for them to take care of their job satisfaction, because these employees react more elastically than with a similar level of satisfaction in large organizations. It is therefore not advisable to underestimate job satisfaction.

In terms of further research in this area, it may be interesting to focus similarly of different segments of employees (e.g. gender, age, marital status). Finding out that some groups of employees respond to job dissatisfaction in different ways can be beneficial for management. Data were collected before the Covid-19 pandemic. It would by therefore also interesting to find out whether this pandemic has in any way been reflected in the issue of job satisfaction and the intention to leave.

At this point, we would also like to mention the limits we see in this study. It is mainly the composition of the sample, which is described in more detail in Table 1. At first glance in the table, it is clear that it is not a representative sample and the general results (for example overall average job satisfaction of the whole sample) should not be generalized to the whole 
population. The problem is, for example, that over $70 \%$ of respondents are women, the sample is relatively more educated than the population and it is mainly represented by the younger generation. The reason is the fact that the criterion for completion the questionnaire was only minimal age of 18 years and continuing gainful activity. Furthermore, it was only at the discretion of the social media group user whether to complete the questionnaire or not. The representation of more educated and young people probably stems from the fact that the completion of the questionnaire presupposes access to the internet and its use during leisure time. To increase representativeness, it would therefore be possible to supplement the data with and offline paper-pencil questionnaire survey. Nevertheless, we believe that partial conclusions can be formed from the data.

Acknowledgments: The realization of this paper was supported by the project GAJU 047/2019/S

\section{References}

Ali, N. (2007). Factors affecting overall job satisfaction and turnover intention. Journal of Managerial Science, 2(2), 240-252.

Alnuaimi, K., Ali, R., \& Al-Younis, N. (2020). Job satisfaction, work environment and intent to stay of Jordanian midwives. International Nursing Review, 67(3), 403-410. https://doi.org/10.1111/inr.12605

Applebaum, D., Fowler, S., Fiedler, N., Osinubi, O., \& Robson, M. (2010). The impact of environmental factors on nursing stress, job satisfaction and turnover intention. The Journal of Nursing Administration, 40(7), 323-238. https://doi.org/10.1097/NNA.0b013e3181e9393b

Artz, B. (2008). The role of firm size and performance pay in determining employee job satisfaction brief: Firm size, performance pay, and job satisfaction. Review of Labour Economics and Industrial Relations, 22(2), 315-343. https://doi.org/10.1111/j.1467-9914.2007.00398.x

Borooah, V. K. (2009). Comparing levels of job satisfaction in the countries of Western and Eastern Europe. International Journal of Manpower, 30(4), 304-325. https://doi.org/10.1108/01437720910973025

Clark, A. E. (1996). Job Satisfaction in Britain. British Journal of Industrial Relations, 34(2), 189-217. https://doi.org/10.1111/j.1467-8543.1996.tb00648.x

Clegg, S. R., \& Bailey, J. R. (2008). International Encyclopedia of Organizational Studies. London: SAGE Publications.

Derby-Davis, M. J. (2014). Predictors of nursing faculty's job satisfaction and intent to stay in academe. Journal of Professional Nursing, 30(1), 19-25. https://doi.org/10.1016/j.profnurs.2013.04.001

Eskildsen, J. K., Kristensen, K., Antvor, H. G. (2010). The relationship between job satisfaction and national culture. The TQM Journal, 22(4), 369-378. https://doi.org/10.1108/17542731011053299

Franěk, M., Mohelská, H., Zubr, V., Bachmann, P., \& Sokolová, M. (2014). Organizational and Sociodemographic Determinants of Job Satisfaction in the Czech Republic. SAGE Open Journal, 4(3), 1-12. https://doi.org/10.1177/2158244014552426

Franěk, M., \& Večeřa, J. (2008). Personal characteristics and job satisfaction. E\&M Ekonomie a Management, 11(4), 63-76.

Güres, C. G., \& Sökmen, A. (2015). Effects of the leadership styles on the organizational commitment, job satisfaction, and intention to leave: A research on Turkish prisons and detention house. Journal of Business Research, 7(3), 59-74. https://doi.org/10.20491/isader.2015315713

Herzberg, F. (1959). The Motivation to Work. New York: Wiley.

Hussein, S., Moriarty, J., Stevens, M., Sharpe, E., \& Manthorpe, J. (2014). Organisational factors, job satisfaction and intention to leave among newly qualified social workers in England. Social Work Education, 33(3), 381-396. https://doi.org/10.1080/02615479.2013.806467

Chou, H. H., Fang, S. C., \& Yeh, T. K. (2019). The effects of facades of conformity on employee voice and job satisfaction. Management Decision, 58(3), 495-509. https://doi.org/10.1108/MD-04-2019-0492

Ingersoll, R. M. (2001). Teacher turnover and teacher shortages: An organizational analysis. American Educational Research Journal, 38(3), 499-543. https://doi.org/10.3102/00028312038003499

Kollárik, T. (1986). Spokojnost’ v práci. Bratislava: Práca. 
Lang, J. R., \& Johnson, N. B. (1994). Job satisfaction and firm size: An interactionist perspective. The Journal of Socio-Economics, 23(4), 405-423. https://doi.org/10.1016/1053-5357(94)90011-6

Locke, E. A. (1976) The Nature and Causes of Job Satisfaction. In Dunnette, M. D. (Ed.), Handbook of Industrial and Organizational Psychology. Chicago: Rand McNally.

Maslow, A. (1943). A Theory of human motivation. Psychological Review, 50(4), 370-396. https://doi.org/10.1037/h0054346

Medgyesi, M., \& Róbert, P. (2003). Satisfaction with work in a European perspective: Center and periphery, „old“ and "new" market economies compared. Review of Sociology, 9(1), 43-68. https://doi.org/10.1556/revsoc.9.2003.1.3

Mobley, W. H. (1982). Some unanswered questions in turnover and withdrawal research. The Academy of Management Review, 7(1), 111-116. https://doi.org/10.2307/257255

Možný, I. (1999). Proč tak snadno? Praha: Slon.

Nakonečný, M. (2005). Sociální psychologie organizace. Praha: Grada.

Park, K. A., \& Johnson, K. R. (2019). Job satisfaction, work engagement, and turnover intention of CTE health science teachers. International Journal for Research in Vocational Education and Training, 6(3), 224-242. https://doi.org/10.13152/IJRVET.6.3.2

Robson, A., \& Robson, F. (2016). Investigation of nurses intention to leave: a study of a sample of UK nurses. Journal of Health Organization and Management, 30(1), 154-173. https://doi.org/10.1108/JHOM-05-2013-0100

Skaalvik, E., \& Skaalvik, S. (2011). Teacher job satisfaction and motivation to leave the teaching profession: Relations with school context, feeling of belonging, and emotional exhaustion. Teaching and Teacher Education, 27(6), 1029-1038. https://doi.org/10.1016/j.tate.2011.04.001

Sokolová, M., \& Mohelská, H. (2019). Job satisfaction as an innovative approach to the management Case study Czech Republic 2013-2017. In 17th International Scientific Conference on Hradec Economic Days. Hradec Králové, University of Hradec Králové. https://doi.org/10.36689/uhk/hed/2019-02-034

Sokolová, M., Mohelská, H., \& Zubr, V. (2016). Pay and offer of benefits as significant determinants of job satisfaction - a case study in the Czech Republic. EEM Ekonomie a Management, 19(1), 108-120. https://doi.org/10.15240/tul/001/2016-1-008

Sousa-Poza, A., \& Henneberger, F. (2004). Analyzing job mobility with job turnover intentions: An international comparative study. Journal of Economic Issues, 38(1), 113-137. https://doi.org/10.1080/00213624.2004.11506667

Štikar, J., Rymeš, M., Riegel, K., \& Hoskovec, J. (2003). Psychologie ve světě práce. Praha: Karolinum.

Tansel, A., \& Gazioglu, S. (2013). Management-Employee Relations, Firm Size and Job Satisfaction. International Journal of Manpower, 35(8), 1260-1275. https://doi.org/10.1108/IJM-09-2014-0179

Tnay, E., Othman, A. E., Siong, H. C., \& Lim, S. (2013). The Influences of Job Satisfaction and Organizational Commitment on Turnover Intention. Procedia - Social and Behavioral Sciences, 97, 201-208. https://doi.org/10.1016/j.sbspro.2013.10.223

Večerník, J. (2003). Skating on thin ice: A comparison of work values and job satisfaction in CEE and EU countries. International Journal of Comparative Sociology, 44(5), 444-471. https://doi.org/10.1177/002071520304400502

Welch, B. L. (1947). The Generalization of Student's Problem when Several Different Population Variances are Involved. Biometrika, 34(1-2), 28-35. https://doi.org/10.1093/biomet/34.1-2.28

Yao, C., \& Huang, P. (2018). Effects of leadership style on job satisfaction and intention to stay in shipping industry. Journal of Coastal Research, 83(1), 796-801. https://doi.org/10.2112/SI83-130.1 